\title{
Resenha
}

ANTOINE, ANDRÉ. Conversas Sobre a Encenação. Tradução, introdução e notas de Walter Lima Torres. Editora 7 Letras, Rio, 2001.

\section{Antoine no Brasil: Ecos de uma velha polêmica}

Edelcio Mostaço

Crítico teatral e professor da Universidade do Estado de Santa Catarina

Não sem tempo, ganha versão brasileira um texto primacial da arte da encenação teatral: Conversas Sobre a Encenação, de André Antoine. Datado de abril de 1903, trata-se de uma curta preleção onde o fundador do Théàtre Libre expõe, para um público interessado mas não profissional, alguns de seus balizamentos estéticos relativos à criação e condução do espetáculo.

A caprichada tradução é de Walter Lima Torres - que lhe acrescentou uma introdução e notas -, além de ajuntar ao volume outro sugestivo e oportuno texto: a conferência que Antoine realiza no Rio de Janeiro, quando de sua excursão pela América Latina. Entre um texto e outro decorrem alguns poucos meses; um funcionando como explicitação do outro, mas albergando o segundo uma resposta a Arthur Azevedo, festejado autor de Teatro a Vapor que, como crítico, não captou a dimensão das inovações.

Comecemos pelo texto histórico. Apontado como o primeiro encenador, no sentido moderno e pleno do termo, somente após longa trajetória artística à frente de seu conjunto de amadores, Antoine lança-se nesta Causerie de la Mise-en-Scène; salientando os principais passos que o conduziram às reformas cênicas, inclusas no âmbito maior do naturalismo estético. Elas podem ser englobadas em três grandes conjuntos; embora cada um tenha suscitado enormes esforços para ser implantado: a demolição das convenções, um novo estilo de interpretação e o uso da iluminação cênica, aproveitando-se da recém descoberta lâmpada elétrica.

O teatro francês vinha amargando, ao longo do século XIX, um pesado tributo às convenções estereotipadas, entendidas desde o respeito ao texto, às

Os textos de Arthur Azevedo dedicados à excursão de Antoine encontram-se republicados in Faria, João Roberto. Idéias Teatrais - o século XIX no Brasil, Editora Perspectiva, São Paulo, 2001, p. 657-670. 
palavras do autor e sua onisciente presença - que, quando mortos, era invocada em espírito; assim como às normas de representação dos atores, bem vigiadas pelo Conservatório ou transmitidas de geração em geração pelo recurso mimético do metièr; isso tudo embalado em cenários falsos, à base de telões pintados e decorados de papier-maché, sem a menor consciência daquilo que, na modernidade, será denominado lugar cênico. O palco era, sempre, o tablado, uma plataforma para dois atores e uma paixão, necessário para garantir a visão das filas mais detrás.

Desde que tais convenções foram conformadas nos séculos XVII e XVIII, encontram amplo lastro na centúria seguinte, incorporadas e redimensionadas pelos estilos vigentes, em que pesem as transformações introduzidas pelo drama romântico e realista. De modo que, mesmo no final do século, recorda Antoine: 'lembrem-se ainda do 'endomingamento' das nossas atrizes. Elas se vestem menos para determinar suas personagens do que para servir de manequins vivos aos costureiros, às modistas" (p. 27). Uma senhora, ao assistir a uma pantomima, comenta com o marido: "eles não estão falando porque hoje é o ensaio geral!", grifa o encenador, retratando não apenas o despreparo das platéias como, sobretudo, sua desconsideração e desconhecimento em relação ao que lhes era apresentado (p. 29).

Após esclarecer seus ouvintes de que um árduo trabalho torna-se imperioso, envolvendo farta equipe técnica e artística, ultimando ínfimos detalhes do produto final antes que a cortina seja aberta, é destacada a importância do regente de todo este processo: o encenador. Para a platéia, quanto mais perfeito o resultado final, menos perceptível é sua figura; escamoteada nas mil e uma soluções com que o artefato final se reveste. Mas sem ele, nada de verdadeiramente artístico se produz no palco.

Distinguindo o ensaiador do encenador, e este do dono de companhia, Antoine finalmente assenta que sua tarefa possui dois planos distintos: um inteiramente material (a constituição do espaço cênico servindo de meio para a ação, a marcação dos atores e o agrupamento das personagens) e uma outra imaterial (a interpretação e o movimento do diálogo). Esta segunda, ainda menos detectada pelo público, implica na orientação ideológica da montagem. É ela quem organizará os signos, dar-lhes-á significados, executará a invisível partitura que combina e coordena todos os ingredientes do espetáculo, conferindo-lhes rumo e forma específica e sintética.

É esta consciência - mas principalmente o exercício desta arte - que alça 
André Antoine à categoria de encenador, em pleno exercício de sua condição. Becq de Fouquières, vinte anos antes, já havia registrado em seu L'Art de la Mise-en-Scène a indispensável instituição desta figura, mas nunca a experimentara na prática. Será no Théàtre Libre que Antoine colocará suas idéias à serviço da renovação naturalista, iniciando a reforma com a abolição dos cenários de papelão, telões pintados e ausência de perspectiva, impondo uma cenografia que reconstruía minuciosamente o ambiente requerido pela ação. Um novo jogo cênico para os atores, agora envolvidos pela "quarta parede", evitava os gestos não-naturais, os apartes, o arraigado hábito de não falar andando, a proibição das costas para a platéia, etc. Um conjunto de hábitos de palco que, aos olhos de hoje, tornam-se quase risíveis. Mas que, durante séculos, sustentaram a arte da declamação dramática. No Brasil, estiveram vigentes até os anos 40 .

A iluminação surge como um recurso à parte: "a luz age fisicamente sobre o espectador: sua magia acentua, sublinha, acompanha maravilhosamente a significação íntima de uma obra dramática. Para obter magníficos resultados não é preciso temer administrá-la, espalhando-a de forma desigual", p. 37, salienta o autor. As lâmpadas incandescentes, inventadas em 1879, já estavam nos teatros em 1880. Elas vão possibilitar a confecção de focos e, daí, o sentido simbólico de foco narrativo, fornecendo ao encenador um poderoso recurso técnico para organizar esteticamente sua obra. Claro que novas convenções são criadas; mas estas exprimem agora o sabor da inovação, nascidas de necessidades internas à obra.

Uma velha tautologia diz que, para que exista teatro, é necessária a interpenetração de três dimensões: o texto, o ator e o público. Para o teatro moderno, contudo, ela deve ser ampliada, incluindo o sentido da leitura, ou seja, o papel do encenador. É ele o responsável pelas interpenetrações aludidas, conferindo à cena um significado que, de outro modo, resultaria acéfalo, desgovernado, sem direção. Esta é a lição aqui em pauta..

\section{No Brasil}

Em sua excursão à América do Sul, em 1903, o Théàtre Antoine (herdeiro do Théàtre Libre) trouxe quase uma vintena de montagens e os principais jornais cariocas escalaram seus críticos para acompanhar a temporada. Athur 
Azevedo escrevia para o Jornal do Commercio. Adepto da peça-bem-feita, uma fórmula nascida ao longo do século XIX e que havia encontrado entre os realistas seus mais tenazes cultores, Azevedo seguia o crítico parisiense Francisque Sarcey letra por letra. E este, fiel defensor das fórmulas consagradas por aquela dramaturgia de algibeira, havia sido o principal alvo do encenador e Emile Zola para imporem suas idéias - e sobretudo seus espetáculos - à capital francesa.

Os conflitos enfrentados pelo naturalismo nos palcos não estiveram longe das mais árduas batalhas. Uma empedernida resistência às novas soluções, mal disfarçadas sob a capa de uma moralidade vitoriana, objetava os avanços. No Brasil, o naturalismo no teatro enfrentou problemas semelhantes, não chegando a impor-se como movimento estético muito palpável; de modo que, em 1903, ainda causava reservas e só penosamente era suportado em cena.

O repertório da excursão incorporava, além de Zola, autores como Ibsen, Bernstein, Sée, Hauptmann, Curel, entre outros, pontas de lança do naturalismo e da peça de tese, um painel das mais expressivas criações da companhia. A inexistência de um aparato de iluminação no Teatro Lyrico, porém, além de sua grandiosidade e existência de largo fosso de orquestra, impediram que as produções recriassem para a platéia carioca toda a intimidade preparada para uma sala de câmara.

Esta é a moldura para a Conferência do Rio de Janeiro, uma prática protocolar destinada à missão cultural (era hábito este esclarecimento das platéias, uma vez que as excursões recebiam auxílios governamentais, incorporadas nas "relações internacionais"); mas que, dada a reação de Azevedo, tornou-se também suporte de uma disputa.

Em sua introdução, Walter Lima esclarece este contexto, bem como o centro da discórdia que se trava entre ambos, envolvendo a pièce-bien-fait, pedra angular e sustentáculo das antigas convenções, das tiradas, da scène à faire, das lições de moral saídas pela boca de um raisonneur. Acrescento eu que ela abarca outros e importantes componentes. Embora elogiando os desempenhos, o dramaturgo brasileiro considera o repertório distante da qualidade esperada; acusa Antoine de repetir-se em suas interpretações e, sobre Honra, de Sudermann (levada no ano anterior pela companhia carioca de Dias Braga), acredita que a montagem brasileira nada deva à parisiense, onde "descontada, porém, a diferença do meio, do ambiente, da educação, do estímulo, dos recursos e, sobretudo, da disciplina, a palma caberia aos nossos" (vide nota).

Ora, a peça-bem-feita reunia o cúmulo das convenções em voga, 
estribada num sistema mercantil que visava quer a bilheteria quanto o conservadorismo de temas, enredos e golpes de teatro que, garantidos pelo hábito, auferissem ampla receptividade. Nosso Sarcey dos trópicos, ao defender esta dramaturgia, apenas corroborava um gosto estético passadista e de calculados resultados, também ele um profissional tão comprometido com a bilheteria quanto os elencos que lhe encomendavam textos.

Trata-se menos de estética o fundo desta discussão, do que de resultados sonantes. A renovação naturalista, exatamente em sentido contrário, visava libertar o palco das antigas normas de mimese, introduzindo narrativas ao modo da tranche de vie, apenas pedaços de vidas comuns enredadas em situações comuns, cotidianas, destituídas de qualquer heroísmo ou efeito outro que não suas angústias, mazelas, obsessões. O proletariado, o homem pobre dos mercados, as lavadeiras, os ceifadores de trigo, contam entre suas personagens de destaque. Compreender isto é compreender o nascimento do teatro moderno, trazido por este drama que efetua um corte experimental na sociedade, golpe certo contra algumas das mais estabilizadas características do aristotelismo cênico.

Esta situação torna-se ainda mais clara quando Azevedo, para defender a prata da casa, cita tudo aquilo que não via em nossos palcos - o meio, o ambiente, a educação, o estímulo, os recursos e sobretudo a disciplina -, exatamente as marcas de trabalho do encenador francês. Ora, tudo isso é fruto da encenação, a materialização do sentido de leitura da obra, inteiramente evaporada na apreensão de nosso crítico a vapor.

Perdeu ele a chance de enxergar exatamente o novo, para onde apontava a renovação cênica naturalista. E, finalmente, ao ver no Antoine ator apenas uma repetição de si mesmo, quando não interpretava papéis elaborados "sob composição", Azevedo deixa de perceber outra de suas decisivas frentes de trabalho, a desmontagem da interpretação tipificada, paradigma que sustentava o medíocre modo de apresentação dos atores correntes.

Foi contra esta declamação exteriorizada, cheia de esgares e trejeitos, em busca dos efeitos fáceis e repetitivos, "solicitando a todo custo a aprovação do público por meio de macetes e truques de mètier", que o encenador colocouse contra; almejando um novo intérprete em que "todo seu físico faz parte de cada personagem representado e que, em certos momentos da ação, suas mãos, suas costas, seus pés podem ser mais eloqüentes do que um longo monólogo; que a cada vez que o ator é percebido sob o personagem, a fábula dramática é interrompida" (p. 39). 
O que aqui temos evocado é o novo ator de matriz psicológica, interiorizado, cercado de intenções e fiel à uma partitura interpretativa concebida rente à evolução dramática de sua alteridade cênica, perfeitamente concretizado, nos anos subsequentes, por Stanislavski. Como se vê, as grossas lentes passadistas de Arthur Azevedo impediram-no de vislumbrar exatamente onde estava o fulcro da renovação cênica de Antoine. Teríamos ainda de esperar quase meio século para que tais conquistas, novamente cruzando o Atlântico, viessem a ser aceitas entre nós, pelas mãos de Os Comediantes.

Possibilitar tais cogitações e reflexões é um mérito trazido por esta oportuna tradução, num momento em que a figura do encenador novamente ocupa o centro do debate. 